\title{
Sinus venous thrombosis: a differential diagnosis of postpartum headache
}

Wittmann, M ; Dewald, D ; Urbach, H ; Gast, A S ; Linnebank, M ; Baumgarten, G ; Knuefermann, P ; Hering, $\mathrm{R}$

\begin{abstract}
In this report, we describe a patient who developed severe headache following epidural analgesia for labor and delivery. Although the epidural puncture had been reported to be uneventful, headache was initially suspected to result from an accidental dural puncture. After the headache worsened, a sinus venous thrombosis was suspected and subsequently confirmed by magnetic resonance imaging. This case highlights the difficulty of differential diagnosis of headache in the postnatal period in patients after EDA and stresses the necessity of considering alternative pathologies.
\end{abstract}

DOI: https://doi.org/10.1007/s00404-011-1964-0

Posted at the Zurich Open Repository and Archive, University of Zurich ZORA URL: https://doi.org/10.5167/uzh-50705

Journal Article

Accepted Version

Originally published at:

Wittmann, M; Dewald, D; Urbach, H; Gast, A S; Linnebank, M; Baumgarten, G; Knuefermann, P; Hering, R (2012). Sinus venous thrombosis: a differential diagnosis of postpartum headache. Archives of Gynecology and Obstetrics, 285(1):93-97.

DOI: https://doi.org/10.1007/s00404-011-1964-0 


\title{
Sinus venous thrombosis: A differential diagnosis of
}

\section{postpartum headache}

\author{
Wittmann $\mathrm{M}^{1}$, Dewald $\mathrm{D}^{1}$, Urbach $\mathrm{H}^{2}$, Gast $\mathrm{AS}^{3}$, Linnebank $\mathrm{M}^{4}$, Knuefermann \\ $\mathrm{P}^{1}$, Hering $\mathrm{R}^{1}$ \\ ${ }^{1}$ Department of Anesthesiology and Intensive Care Medicine, University Hosptial Bonn, Germany, ${ }^{2}$ Department of Neuroradiology, \\ University Hosptial Bonn, Germany, ${ }^{3}$ Department of Gynecology and Obstetrics, Center for integrated Oncology, University Hosptial Bonn, \\ Germany, ${ }^{4}$ Department of Neurology, University Zürich, Switzerland.
}

Corresponding author: $\quad$ Pascal Knüfermann, MD

Department of Anesthesiology and

Intensive Care Medicine

Sigmund-Freud-Str. 25

D-53105 Bonn

Phone: +49-228-287-14112

Fax: +49-228-287-14125

E-mail: pascal.knuefermann@ukb.uni-bonn.de 


\begin{abstract}
In this report we describe a patient who developed severe headache following epidural analgesia for labor and delivery. Although the epidural puncture had been reported to be uneventful, headache was initially suspected to result from accidently dural puncture. After the headache worsened a sinus venous thrombosis was suspected and subsequently confirmed by magnetic resonance imaging. This case highlights the difficulty of differential diagnoses of headache in the postnatal period in patients after epidural analgesia and stresses the necessity of considering alternative pathologies.
\end{abstract}

Key words: epidural analgesia, headache, sinus venous thrombosis, obstetrics, complications

\title{
Introduction:
}

Cerebral venous thrombosis (CVT) is a rare diagnosis characterized by symptoms like headache, nausea, vomiting, focal neurological deficits and epileptic seizures. It is associated with the use of oral contraceptives, pregnancy and the puerperium, obesity, and other diseases. Without adequate therapy, CVT often leads to severe outcome [1]. Here, we report a case of CVT that occurred after epidural analgesia for labor to highlight the difficulty of such diagnosis in the presence of postural headache. We emphasize the importance of careful reviewing potential differential diagnoses of postural headache and the difficulty of differentiating rare from common diagnoses.

Case report: A previously healthy 29-year old woman, ASA 2, gravida 2, para 1 was admitted to the delivery room of the University Hospital Bonn at term in active labor. The medical history was significant only for a deep venous thrombosis during recovery from a 
knee surgery six years ago. Her obstetrical history was significant for an abortion and a still birth. Before her pregnancy she was taking no medication and was a non-smoker. During the pregnancy she underwent a hemostaseologic consultation, where a pregnancy-related hypercoagulable state with an elevated Factor VIII activity was diagnosed. To prevent recurrent deep vein thrombosis the patient received nadroparine calcium subcutaneously at a dose of $0.3 \mathrm{ml}$ per day starting six weeks before the anticipated date of delivery. In the third trimenon, placental insufficiency was suspected by dopplersonographic examination and an additional low-dose antiplatelet therapy with $100 \mathrm{mg} /$ day acetylsalicylic acid was initiated.

The patient appeared for delivery in the $37+1$ week of pregnancy. For treatment of first stage labor pain the parturient received epidural analgesia after a successful placement of an epidural catheter on the first attempt under aseptic conditions. Using the loss of resistance to saline technique an epidural catheter was introduced into the lumbar epidural space at the L 34 interspace using a $18 \mathrm{G}$ Tuohy needle. Injection of a bupivacain test dose $(12.5 \mathrm{mg})$ showed no signs of intravascular or intrathecal action. Subsequent administration of $12 \mathrm{ml}$ of a solution containing $18 \mathrm{mg}$ ropivacaine and $6 \mu \mathrm{g}$ sufentanil produced excellent analgesia. Six hours after insertion of the epidural catheter the patient had a spontaneous vaginal delivery of a healthy infant. The catheter was removed 12 hours after delivery by an anesthesiologist. The neurological examination was negative and inspection of the puncture site showed no signs of infection.

On the first day postpartum the patient complained of moderate occipital emphasized headache. Since the headache had no significant clinical character and since the patient did not show any neurological symptoms, the patient was discharged the same day. Medication with nadroparine calcium was re-initiated.

Twenty-eight days postpartum the patient presented in a moderately reduced general condition and complained of persistent severe headache and nausea. The patient reported continuously aggravating postural headache, predominantly located in the neck and both eyes, 
which becomes worse in the upright position and markedly improves by taking a supine position. On clinical examination she was normotensive, had no fever and the site of epidural puncture did not show any sign of redness, swelling or irritation. A postdural puncture headache was suspected and after anesthesiological consultation a magnetic resonance imaging (MRI) of the lumbar spine was done to exclude an inflammation of the puncture site. Further neurological examination in the department of neurology showed no neurological deficit. However, since epidural puncture had been reported to be uneventful the differential diagnosis of meningitis or CVT was taken into consideration. At her own request, the patient was discharged on analgesic medication.

The patient returned on the next day due to a clinical deterioration to the hospital. At this point, she presented with severe headache, slightly reduced consciousness and bloodshot conjunctiva of the right eye. The diagnosis of cerebral venous thrombosis (CVT) was suspected, although the patient received thrombosis prophylaxis with nadroparine calcium starting six weeks before the anticipated date of delivery. Magnetic resonance imaging (MRI) of the brain revealed a right parietal hypodensity on FLAIR and T2-weighted images, a delta sign and small ventricles. Magnetic resonance angiography showed thrombosis of superior, sagittal and transverse sinuses. Furthermore, a small congestive intraparenchymal bleeding in the right occipital region was detected. The patient was admitted to the stroke unit and anticoagulation with high dose intravenous heparin was immediately initiated. Blood tests showed elevated D-dimers of $3.39 \mu \mathrm{g} / \mathrm{ml}$ (normal range: $0-0.49 \mu \mathrm{g} / \mathrm{ml}$ ). Specific neurological examination showed a papilloedema in the right eye with minimal bleeding signs, but no neurological deficit. A control MRI after $24 \mathrm{hr}$ demonstrated a further enlargement of the thrombus now reaching into the right internal jugular vein. One week after readmission the patient developed a symptomatic paresis of the right abducens nerve, which persisted for the next three months. 
During the further clinical course the patient's condition and MRI results improved markedly. Clinical and laboratory work-up revealed no risk factors for recurrent thrombosis in the patient except for a moderate increase in lipoprotein a. After four weeks in the hospital, the patient was discharged in a good condition with oral anticoagulation therapy. At the time of the last follow-up (nine months postpartum) the patient showed no neurological deficit. After 12 months postpartum the anticoagulation regime was modified to a low dose therapy.

\section{Discussion:}

Postpartum period is a high risk situation for all kind of complications, because of rearrangement of the maternal cardiovascular circulation. Also neurological symptoms, like headache, can occur and are often caused by sleep deprivation, irregular food intake, or dehydration. All these factors in addition to hormonal fluctuations in estrogen level may lead to postpartum headache [2]. Postpartum headache can be classified as primary or secondary. Primary headaches include migraine, tension-type, cervicogenic, and cluster headache. Secondary headache can emerge after complications of regional anesthesia (e.g., postdural puncture headache (PDPH)), obstetrical disease (e.g. preeclampsia), or intracranial pathology (e.g. cerebral venous thrombosis). Goldszmidt et al. reported in a cohort study a headache incidence of $39 \%$ in the first postpartum week. Most of the postpartum headache were primary in nature (>75\%) and PDPH accounted for $4.7 \%$ [3]. The typical parturient who complains of a postpartum headache is usually treated with analgesics and can be discharged when symptoms are declining under medication. Whenever headache is persistent despite the use of analgesics and/or neurological symptoms or even when further deficits occur, a multidisciplinary evaluation with appropriate therapy is required to prevent possible lifethreatening complications from secondary causes of headache. Because the features of various types of postpartum headache overlap, differentiation and recognition of right diagnosis is difficult. 
The presented case is an excellent example for the diagnostic challenge of a CVT presenting in the postpartum period. Although the epidural catheter placement showed no indication of an unintentional dural puncture and the following delivery was uneventful, the first suspected diagnosis was postdural punction headache (PDPH).

Epidural anesthesia is a common technique for providing analgesia during labor and delivery. Approximately $60 \%$ of women choose epidural analgesia (EDA) or combined spinal-epidural analgesia for pain relief during labor in the US [4]. A survey in Germany showed that $54 \%$ of hospitals often use epidural analgesia, while $44 \%$ do so occasionally for pain relief during delivery [5]. The most frequent complication during the placement of an epidural catheter is an unintended puncture of the subarachnoid space that occurs in about $1.5 \%$ of parturient women. Up to $70 \%$ of women develop postdural puncture headache (PDPH) afterwards [6]. Spinal headache typically occurs within three days after the procedure. The headache is often described as a severe `searing and spreading like hot metal`. The common distribution is over the frontal and occipital areas radiation to the neck and shoulders. The pain is exacerbated by head movement and adoption of the upright posture and relieved by lying down. Other symptoms associated with PDPH include nausea, vomiting, hearing loss, tinnitus, vertigo and dizziness. Cranial nerve palsies are described and neurological symptoms may precede the onset of grand mal seizures [7]. The symptomatic therapy includes bed rest in supine position, analgesics and intravenous hydration. Various drugs are recommended for symptomatic pain relief (e.g. caffeine, sumatriptan, methergine); however, in most cases there is no evidence for sufficient therapeutic effect. When conservative management is insufficient or headache intensity is severe, an epidural blood patch is frequently performed [8].

In a situation where postpartal headache occurs in the absence of accidental dural puncture it is important to exclude possible severe complications. In our case the consulted anesthesiologist in the department of obstetrics arranged a MRI of the lumbar spine to exclude other local complications in relation to the epidural analgesia. Although major 
complications of central neuraxial blocks, e.g. epidural abscess, nerve injury and vertebral canal hematoma are very rare (4.2 per 100000$)$, they can result in irreversible damage if not treated immediately [9].

In our case, considering the previous history of deep venous thrombosis and a known elevated factor VIII activity, a cerebral venous thrombosis was an important differential diagnosis of postpartum headache. CVT is a rare postpartal event (10-20 cases per 100000 deliveries in the US and Western Europe) due to hypercoagulability [10]. A CVT can be easily missed due to the wide range of clinical symptoms and signs, which overlap with other forms of headache. In addition, this case shows that CVT may even occur despite prophylactic anticoagulation therapy. The most frequent symptom of CVT is constant or postural headache (70-88 \%). Symptoms may also include dizziness, nausea, vomiting, blurred vision, neurologic signs, papilloedema, lethargy, seizures, and coma [11,12]. It usually increases gradually over a couple of days, but it can also start rapidly while mimicking a subarachnoid hemorrhage. The specific presentation depends on location and extend of the thrombosis, the degree of collateral venous circulation, and the presence of associated cortical lesions. In addition, symptoms may fluctuate as thrombosis and fibrinolysis occur simultaneously, leading to changes in surrounding blood flow and intracranial pressure [13]. The presented case is an example for possible symptom fluctuation. After amelioration of the headache and signs of thrombus organization, the patient developed a paresis of the right abducens nerve. Two major studies aimed to investigate the prognosis and long-term outcome of CVT (ISCVT [14] and VENOPORT $[15,16])$. In summary, all these studies confirm that patients with CVT have a rather good prognosis. Mortality rates are $5.6 \%$ in acute phase and $9.4 \%$ after 12 months, most patients reach a complete recovery $[17,18]$. Ferro et al. developed a risk score to predict the outcome of patients with CVT (hazard ratio: malignancy 4.53, coma 4.19, thrombosis of the deep venous system 3.03, mental status disturbance 2.18, male gender 1.60, intracranial haemorrhage 1.42) [19]. 
The diagnostic methods of choice for CVT are MRI and magnetic resonance venography [20], whereas a computed cranial tomography appears normal in up to $26 \%$ [21]. The use of Ddimer as a diagnostic marker has been explored in small studies, but the results are nonconclusive [22].

The treatment of CVT is primarily supportive, although endovascular thrombolysis and surgical thrombectomy are considered in severe cases [23]. Anticoagulation seems to be the treatment of choice $[24,25]$. However, the authors of a Cochrane systematic review could not find any randomized controlled trial that evaluates the efficacy of thrombolysis in acute CVT [24]. Vitamin K antagonists remain the drugs of choice for the long term, secondary prevention of CVT. A European guideline suggests continuation of anticoagulation for a period of three months if the CVT was secondary to a transient risk factor and for 6-12 months in patients with idiopathic CVT as well as in those with "mild" thrombophilia. Indefinite anticoagulation should be considered in patients with recurrent episodes of CVT and in those with a simple episode of CVT and concomitant 'severe' thrombophilia [25]. In our case the patient received intravenous heparin followed by a vitamin $\mathrm{K}$ antagonist for 12 months. Afterwards the therapy was modified to life-long low-dose anticoagulation considering her elevated risk and for thromboses.

In conclusion, CVT is a rare entity that often presents as a postural headache resulting from thrombosis of the cerebral veins and/or venous sinuses. This case shows the rare coincidence of suspected spinal headache and a CVT. The report emphasizes the importance of carefully reviewing potential differential diagnoses of postural headache and the difficulty of discerning rare from common diagnoses. An algorithm for the management of servere postpartum headache, as proposed by Stella et al., could help in this evaluation process [2]. Finally this case stresses the importance of interdisciplinary collaboration to provide optimal health care in the peripartum period.
Kommentar [ML3]: unsere neuroradiologen behaupten, ct sei besser, ich finde es zumindest gleichwertig. das gilt, wenn die venöse phase im ct-angio dargestellt wird, das normale ct ist in der Tat wenig aussagekräftig. am besten schreiben wir allgemein, dass zu diagnostik geeignete sequenzen in mri oder ct genutzt werden können. 


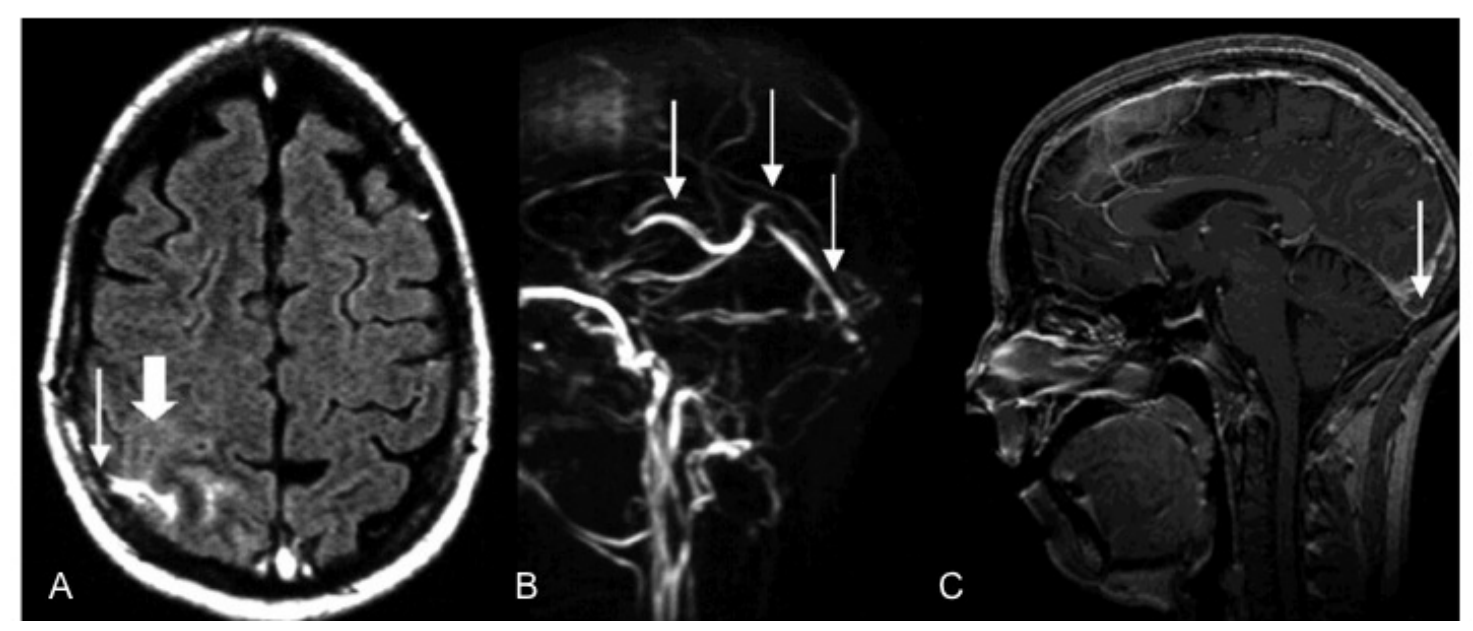

Figure 1: Axial FLAIR fast spin echo sequence (A) shows thrombosed superior sagittal sinus and bridging vein (arrow) as well as congestion oedema in the right parietal lobe (thick arrow). Sagittal maximum intensity projection of a 3D phase contrast magnetic resonanceangiogram; (B) demonstrates flow in the internal cerebral veins, vein of Galen and straight sinus (arrows), but not in the superior sagittal sinus. Sagittal 3D T1-weighted gradient echosequence following Gd-DTPA-administration (C) displays thrombus in the posterior superior sagittal sinus (arrow).

\section{References}

1. Agostoni E, Aliprandi A, Longoni M (2009) Cerebral venous thrombosis. Expert Rev Neurother 9 (4):553-564. doi:10.1586/ern.09.3 [doi]

2. Stella CL, Jodicke CD, How HY, Harkness UF, Sibai BM (2007) Postpartum headache: Is your work-up complete? Am J Obstet Gynecol 196 (4):318.e311-317. doi:10.1016/j.ajog.2007.01.034

3. Goldszmidt E, Kern R, Chaput A, Macarthur A (2005) The incidence and etiology of postpartum headaches: A prospective cohort study. Can J Anaesth 52 (9):971-977. doi:52/9/971 [pii]

10.1007/BF03022061

4. Bucklin BA, Hawkins JL, Anderson JR, Ullrich FA (2005) Obstetric anesthesia workforce survey: Twenty-year update. Anesthesiology 103 (3):645-653. doi:00000542-20050900000030 [pii]

5. Bartusseck E, Fatehi S, Motsch J, Grau T (2004) Umfrage zur aktuellen situation der regionalanästhesie im deutschsprachigen raum - teil 3: Verfahren der geburtshilflichen anästhesie. Anaesthesist 53 (10):993-1000. doi:10.1007/s00101-004-0719-8

6. Kessler P, Wulf H (2008) Duraperforation-postpunktioneller kopfschmerz. Anasthesiol Intensivmed Notfal 5:346-352 
7. Turnbull DK, Shepherd DB (2003) Post-dural puncture headache: Pathogenesis, prevention and treatment. Br J Anaesth 91 (5):718-729

8. Thew M, Paech MJ (2008) Management of postdural puncture headache in the obstetric patient. Curr Opin Anaesthesiol 21 (3):288-292. doi:10.1097/ACO.0b013e3282f8e21a [doi] 00001503-200806000-00007 [pii]

9. Cook TM, Counsell D, Wildsmith JA (2009) Major complications of central neuraxial block: Report on the third national audit project of the royal college of anaesthetists. $\mathrm{Br} \mathrm{J}$ Anaesth 102 (2):179-190. doi:aen360 [pii]

$10.1093 / \mathrm{bja} / \mathrm{aen} 360$

10. Lockhart E, Baysinger C (2007) Intracranial venous thrombosis in the parturient. Anesthesiology 107 (4):652-658; quiz 687-658. doi:10.1097/01.anes.0000282103.70955.c4 [doi]

00000542-200710000-00021 [pii]

11. Ferro JM, Canhao P, Stam J, Bousser MG, Barinagarrementeria F (2004) Prognosis of cerebral vein and dural sinus thrombosis: Results of the international study on cerebral vein $\begin{array}{llllll}\text { and dural sinus thrombosis (iscvt). Stroke } 35 & \text { (3):664-670. }\end{array}$ doi:10.1161/01.STR.0000117571.76197.26

01.STR.0000117571.76197.26 [pii]

12. Wasay M, Bakshi R, Bobustuc G, Kojan S, Sheikh Z, Dai A, Cheema Z (2008) Cerebral venous thrombosis: Analysis of a multicenter cohort from the united states. J Stroke Cerebrovasc Dis 17 (2):49-54. doi:S1052-3057(07)00186-3 [pii]

10.1016/j.jstrokecerebrovasdis.2007.10.001

13. Cantu C, Barinagarrementeria F (1993) Cerebral venous thrombosis associated with pregnancy and puerperium. Review of 67 cases. Stroke 24 (12):1880-1884

14. Ferro JM, Canhão P, Stam J, Bousser M-G, Barinagarrementeria F, Investigators I (2004) Prognosis of cerebral vein and dural sinus thrombosis: Results of the international study on cerebral vein and dural sinus thrombosis (iscvt). Stroke 35 (3):664-670. doi:10.1161/01.STR.0000117571.76197.26

15. Ferro JM, Lopes MG, Rosas MJ, Ferro MA, Fontes J, Group CVTPCS (2002) Long-term prognosis of cerebral vein and dural sinus thrombosis. Results of the venoport study. Cerebrovasc Dis 13 (4):272-278

16. Gosk-Bierska I, Wysokinski W, Brown RD, Karnicki K, Grill D, Wiste H, Wysokinska E, McBane RD (2006) Cerebral venous sinus thrombosis: Incidence of venous thrombosis


doi:10.1212/01.wnl.0000233887.17638.d0

17. Dentali F, Ageno W (2010) Cerebral vein thrombosis. Intern Emerg Med 5 (1):27-32. doi:10.1007/s11739-009-0329-1

18. Dentali F, Ageno W (2007) Natural history of cerebral vein thrombosis. Curr Opin Pulm Med 13 (5):372-376. doi:10.1097/MCP.0b013e3282058b81

19. Ferro JM, Bacelar-Nicolau H, Rodrigues T, Bacelar-Nicolau L, Canhão P, Crassard I, Bousser M-G, Dutra AP, Massaro A, Mackowiack-Cordiolani M-A, Leys D, Fontes J, Stam J, Barinagarrementeria F, investigators IaV (2009) Risk score to predict the outcome of patients with cerebral vein and dural sinus thrombosis. Cerebrovasc Dis 28 (1):39-44. doi:10.1159/000215942

20. Bousser MG, Ferro JM (2007) Cerebral venous thrombosis: An update. Lancet Neurol 6 (2):162-170. doi:S1474-4422(07)70029-7 [pii]

10.1016/S1474-4422(07)70029-7

21. Anxionnat R, Blanchet B, Dormont D, Bracard S, Chiras J, Maillard S, Louail C, Moret C, Braun M, Roland J, et al. (1994) Present status of computerized tomography and angiography in the diagnosis of cerebral thrombophlebitis cavernous sinus thrombosis excluded. J Neuroradiol 21 (2):59-71 
22. Crassard I, Soria C, Tzourio C, Woimant F, Drouet L, Ducros A, Bousser MG (2005) A negative d-dimer assay does not rule out cerebral venous thrombosis: A series of seventythree patients. Stroke 36 (8):1716-1719. doi:01.STR.0000173401.76085.98 [pii]

10.1161/01.STR.0000173401.76085.98

23. Philips MF, Bagley LJ, Sinson GP, Raps EC, Galetta SL, Zager EL, Hurst RW (1999) Endovascular thrombolysis for symptomatic cerebral venous thrombosis. J Neurosurg 90 (1):65-71. doi:10.3171/jns.1999.90.1.0065 [doi]

24. Stam J, De Bruijn SF, DeVeber G (2002) Anticoagulation for cerebral sinus thrombosis. Cochrane Database Syst Rev (4):CD002005. doi:10.1002/14651858.CD002005

25. Einhaupl K, Stam J, Bousser MG, De Bruijn SF, Ferro JM, Martinelli I, Masuhr F (2010) Efns guideline on the treatment of cerebral venous and sinus thrombosis in adult patients. Eur J Neurol 17 (10):1229-1235. doi:ENE3011 [pii]

10.1111/j.1468-1331.2010.03011.x 